\title{
Defective Thyroglobulin Synthesis
}

National Cancer Institute

\section{Source}

National Cancer Institute. Defective Thyroglobulin Synthesis. NCI Thesaurus. Code C131431.

Impairment in the intracellular synthesis of thyroglobulin. 